\title{
A Comprehensive Evaluation and Research of Water Resources Allocation Plans Based on Fuzzy Set Pair Analysis
}

\author{
Yang Bo \\ Hubei University of automotive Technology \\ Shiyan, China \\ ybo1206@163.com
}

Mei Ye

School of Electrical \& Information Engineering

Hubei University of automotive Technology

Shiyan, China

303264669@qq.com

\author{
Yang Junjie* \\ School of Information and Technology \\ Zhanjiang Normal University \\ Zhanjiang, China \\ jjyang2013@163.com
}

Wu Tao

School of Information and Technology

Zhanjiang Normal University

Zhanjiang, China

2718399@qq.com

\begin{abstract}
Multi-attributes decision-making method based on fuzzy set pair analysis can effectively describe and process uncertain information when making decisions. The research mainly focuses on water resources allocation plans of northern China. By applying multi-attributes decisionmaking method, it can help to choose the best water resources allocation plan through its comprehensive evaluation. And the evaluation result proves to be reasonable in the end. This provides an effective way to solve uncertain synthesis decision-making problems of regional water resources.
\end{abstract}

Keywords- fuzzy decision-making; set pair analysis; water resources; optimal assessment; uncertaint;

\section{INTRODUCTION}

The global "water crisis" problem has received worldwide attention. Phenomena like flooding, droughts, soil erosion and water pollution are either caused by natural factors or human factors. And one effective way to alleviate water crisis is to strengthen integrated management of regional water resources, so that the research on decision-making analysis of water resources management is of great importance.

The water resource management based on the concept of sustainable use consists of a large number of multiple attributes evaluations and decision-making problems. For example, evaluations on water quality, water resources development and utilization, environmental effect of water conservancy project, aquatic ecosystems, water resource carrying capacity, decisionmaking analysis of water resources allocation plans, managing efficiency of water resources, etc. [1] The systematic study on water resources can improve and develop multi-attributes decision-making theories and methods, so that evaluation and decision-making of water resources can be built on a more scientific and systematic theoretical basis. Moreover, more information can be provided to solve practical problems on engineering scientifically.

SPA (Set Pair Analysis) is a kind of system analysis method used to study uncertain system which was proposed by Zhao Keqin [2,3,4,5]. SPA uses correlate to describe all kinds of uncertain information within a system, it is a kind of approximate description of a system $[6,7,8]$. And the multi-attributes decision-making method based on fuzzy set pair analysis is an effective method to study decision-making problems of uncertain multi-attributes by using fuzzy numbers to redefine correlate. In the decisionmaking research of water resources management, the barrier is how to understand and describe all kinds of uncertainty and fuzziness during the decision-making process. This thesis aims to study the regional water resources planning problem under an uncertain environment by setting the comprehensive evaluation of water resources plans as a target and applying the multiattributes decision-making method to deal with uncertainty and fuzziness in the decision-making process.

\section{DECISION-MAKING METHOD OF FUZZY SET PAIR ANALYSIS}

A Multi- attributes decision-making (MADM) is of the form $D(A, U, W, F)$, where $A=\left\{A_{l}\right\}$ denotes discrete set of alternative schemes; $U=\left\{U_{k}\right\}$ is set of attributes; $F=\left\{f_{k l}\right\}_{m \times n}$ denotes the decision matrix, where $f_{k l}$ is attribute of $U_{k}$ at $A_{l} ; W=\left\{w_{k}\right\}$ represents the weights on attribute set $U, R=\left\{r_{k l}\right\}_{m \times n}$ is the relative membership degree matrix with regard to $F$. 
$R^{+}=\left\{r_{k}^{+}\right\}$is ideal scheme of $\boldsymbol{R}, r_{k}^{+}=\max _{l}\left(r_{k l}\right)$, and $R^{-}=\left\{r_{k}^{-}\right\} \quad$ is negative ideal scheme of $\boldsymbol{R}$, $r_{k}^{-}=\min _{l}\left(r_{k l}\right), \quad k=1,2 \cdots, m, \quad l=1,2, \cdots, n$ 。

When using SPA to study multi-attributes decisionmaking problems, alternative A and ideal alternative $R^{+}$

$\left(R^{-}\right)$of a decision matrix are combined to form set pairs, and then the correlates of these set pairs will be defined in a relatively close extent. If the corresponding correlate of alternative $\mathrm{A}$ is set as $\mu_{l}=a_{l}+b_{l} i+c_{l} j$ and the elements of $\mathrm{W}$ and $\mathrm{F}$ are triangular fuzzy numbers, $\widetilde{R}=\left\{r_{k l}^{l}, r_{k l}^{m}, r_{k l}^{r}\right\}_{m \times n}$

$\tilde{\mathrm{W}}=\left\{w_{k}^{l}, w_{k}^{m}, w_{k}^{r}\right\} \quad, \quad \tilde{R}^{+}=\left\{r_{k}^{+l}, r_{k}^{+m}, r_{k}^{+r}\right\}$

$\tilde{R}^{-}=\left\{r_{k}^{-l}, r_{k}^{-m}, r_{k}^{-r}\right\}$, the correlate of alternative $A_{l}$ will be $\tilde{\mu}_{l}=\tilde{a}_{l}+\tilde{b}_{l} i+\tilde{c}_{l} j$, and the definition of $\tilde{a}_{l}$ and $\tilde{c}_{l}$ are as follows [9]:

$$
\begin{aligned}
& \tilde{a}_{l}=\left(\sum_{k=1}^{m} w_{k}^{l} \cdot a_{k l}^{l}, \sum_{k=1}^{m} w_{k}^{m} \cdot a_{k l}^{m}, \sum_{k=1}^{m} w_{k}^{r} \cdot a_{k l}^{r}\right) \\
& \tilde{c}_{l}=\left(\sum_{k=1}^{m} w_{k}^{l} \cdot c_{k l}^{l}, \sum_{k=1}^{m} w_{k}^{m} \cdot c_{k l}^{m}, \sum_{k=1}^{m} w_{k}^{r} \cdot c_{k l}^{r}\right)
\end{aligned}
$$

where

$\tilde{a}_{k l}=\left(\frac{r_{k l}^{l}-r_{k}^{-r}}{r_{k}^{+r}}, \frac{r_{k l}^{m}-r_{k}^{-m}}{r_{k}^{+m}}, \frac{r_{k l}^{r}-r_{k}^{-l}}{r_{k}^{+l}}\right)$

$\tilde{c}_{k l}=\left(\frac{r_{k}^{-l}\left(r_{k}^{+l}-r_{k l}^{r}\right)}{r_{k l}^{r} \cdot r_{k}^{+r}}, \frac{r_{k}^{-m}\left(r_{k}^{+m}-r_{k l}^{m}\right)}{r_{k l}^{m} \cdot r_{k}^{+m}}, \frac{r_{k}^{-r}\left(r_{k}^{+r}-r_{k l}^{l}\right)}{r_{k l}^{l} \cdot r_{k}^{+l}}\right)$

For connection numbers $\tilde{\mu}_{l}$, by calculating its relatively certainty probability power $P\left(\tilde{\mu}_{l}\right)$ to judge the distance between corresponding decision-making alternative and ideal alternative. The larger $P\left(\tilde{\mu}_{l}\right)$ is, the better and nearer the decision-making alternative is to the ideal alternative, and vise versa. And $P\left(\tilde{\mu}_{l}\right)$ of $\tilde{\mu}_{l}$ can be defined as :

$$
P\left(\tilde{\mu}_{l}\right)=\left(\frac{2 a_{l}^{l}}{1-a_{l}^{l}}-\frac{c_{l}^{r}}{1-c_{l}^{r}}, \frac{2 a_{l}^{m}}{1-a_{l}^{m}}-\frac{c_{l}^{m}}{1-c_{l}^{m}}, \frac{2 a_{l}^{r}}{1-a_{l}^{r}}-\frac{c_{l}^{l}}{1-c_{l}^{l}}\right)
$$

By calculating entropy, the objective weight of different targets can be determined[11]. If the objective weight of index $K$ is set as $\tilde{\mathrm{W}}_{o k}=\left\{w_{o k}^{l}, w_{o k}^{m}, w_{o k}^{r}\right\}$, the formula will be:

$$
w_{o k}=\frac{1-H_{k}}{\sum_{i=1}^{m}\left(1-H_{i}\right)}
$$

where,

$$
H_{k}=-\frac{1}{\ln n}\left(\sum_{l=1}^{n} f_{k l} \ln f_{k l}\right), \quad f_{k l}=\frac{r_{k l}}{\sum_{l=1}^{n} r_{k l}} 。
$$

So if subjective weight $w_{s k}$ is involved in, the comprehensive weight $w_{k}$ of evaluation index will be:

$$
w_{k}=\frac{w_{s k} \times w_{o k}}{\sum_{i=1}^{m}\left(w_{s k} \times w_{o k}\right)}
$$

\section{THE COMPREHENSIVE EVALUATION OF WATER RESOURCES PLANS}

It is important to optimize water resources allocation plans in water resources systems analysis. The evaluation object of the research are 6 water resources allocation plans of northern China and 20 indexes of each plan as predicted values in 2010. And the aim is to see how the proposed decision-making methods work in the comprehensive evaluation of water resources plans. Table 1 shows a decision matrix, and U1、U2、U3、U6、U7、 U8、U9 are "benefit type" attributes, others are "cost type" attributes. And table 2 shows the relative membership degree matrix of a decision matrix.

TABLE I. THE INVESTMENT AND ANTICIPATED BENEFITS OF WATER RESOURCES ALLOCATION PLANS OF NORTHERN CHINA IN 2010

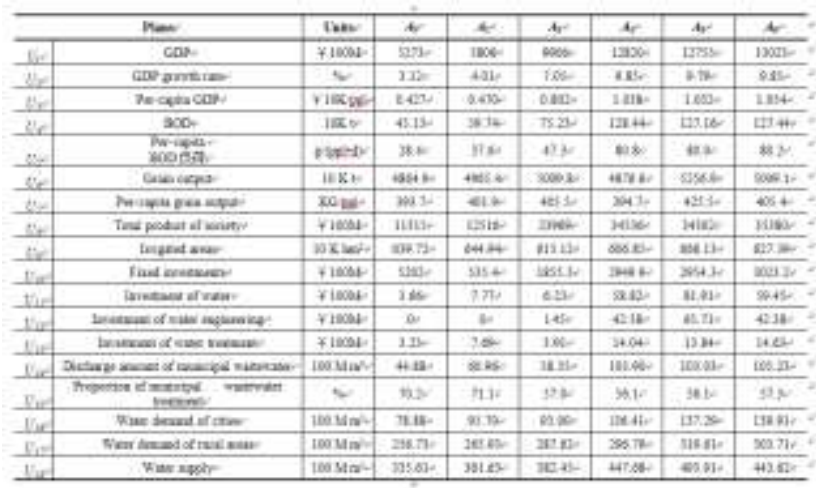


TABLE II. TABLE 2 THE RELATIVE MEMBERShIP DEgREE MATRIX

\begin{tabular}{|c|c|c|c|c|c|c|}
\hline Plaus - & A) & $A_{r}$ & As & $A_{4}$ & 4 & $A_{4}$ \\
\hline $\mathrm{Ce}$ & 0.213 & 0.2533 & 0.0281. & 0.9738 & 0.9653 & 1 \\
\hline$c_{4}$ & 0.14174 & 0217. & 0.5663. & 4. & $09007-$ & 12 \\
\hline $\mathrm{cot}^{-}$ & $0.16+1-$ & $0,108$. & $0.57 \%$ & $0,0<03$. & 09587. & if \\
\hline$c_{4}$ & 1. & 0.5707. & 0.3509 & 0.1233. & $0.125-$ & 0.1254 \\
\hline $\mathrm{C}_{\mathrm{g}}$ & If & 0.5705 & 03805 . & 0.1235 & 0.128 & 0.1254 \\
\hline c. & 0.3127 & 0425. & 04857. & 03242 & 1. & $0+5470^{\circ}$ \\
\hline$c$ & 0319 & 0.4349. & 0.4857 & 0324 & 1. & 0.4839 \\
\hline $\mathrm{G}_{2}$ & 0,1023 & Q 1251. & $0 .+48$. & 0.9529. & 09. & 1 \\
\hline$C_{1}$ & (1.4453- & 0.52130 & 02093 & 0 Isso & 3. & 0.3017 \\
\hline $\mathrm{Cu}_{\mathrm{w}}$ & 0,1029 & 1. & 0.2885 & 0.1515. & 0.1812 & 01711 \\
\hline civ & 18 & 0.471 & 0.5875 & 0.08226 & 004470 & $0.0016=$ \\
\hline $\mathrm{Cox}^{2}$ & 1. & 1. & 0.9893. & 0.584. & $0.03-$ & 0354 \\
\hline Cur & 1. & $0,42+$ & $0826 \mathrm{t}$ & $0.2301 \mathrm{t}$ & 02334 & $0.2 \times 8$ \\
\hline C.r & 14 & 0.542. & 0 seis & 0.1866. & 0.1527 & O.18I8 \\
\hline$C_{y}$ & 0.1683 & 0.15024 & 03804 & t. & 1. & 0.542 \\
\hline cir & 14 & 0.86. & 0.6102 & 0.194. & 01507. & 01702 \\
\hline $\mathrm{CH}$ & 1. & 0.7816 & 04514 & bys:4. & 02158 & 6304 \\
\hline $\mathrm{Car}$ & 0147 & 0.2104 & 02784 & 0.0118 & 10 & 0.9845 \\
\hline
\end{tabular}

Table 3 shows objective weight of different attributes by the relative membership degree matrix.

TABLE III. TABLE 3 THE OBJECTIVE WEIGHT

\begin{tabular}{|c|c|c|c|c|c|c|c|c|}
\hline Amrituln & 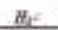 & $w_{i t}$ & Alinturew & $\ddot{H F}_{\mathrm{r}}$ & $W_{i t}$ & Atrohesese & $\mathrm{Hr}$ & $w_{u r}$ \\
\hline He & 992 & 3050 & the & 6.942. & 0.59 & 50 & isgl. & 30555 \\
\hline 4:- & 1 pias. & ansis. & $t_{x}$ & osme. & essis? & $\mathrm{Br}$ & in: & losss- \\
\hline $3 r$ & 20000 & ogsts & 4 & (.si) & onsis & tive & axps: & $\operatorname{coss}$ \\
\hline 48 & 68214 & 90800 & $v_{i y}$ & chas? & Q05s! & 48 & 98911 & $30555=$ \\
\hline th & ang1: & 20080 & $t_{u s}$ & 0.7352 & essen. & $v_{1}$ & 00280 & 10552 \\
\hline tir & oever. & actso- & Liv & $0 \mathrm{cms}$ & Dosss & Sin & amas & 30 sese \\
\hline
\end{tabular}

Table 4 shows the comparison results by using weighting method, FMEA[10] and SPA.

TABLE IV. TABle 4 The Result of Evaluation IndeX

\begin{tabular}{|c|c|c|c|c|c|c|}
\hline 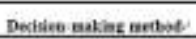 & $A_{t}$ & 4 & $A_{0}$ & dr & 4 & $A^{2}$ \\
\hline Wrighing mentad:- & 05613. & 0.5625. & 05354 & $0 .+5003$, & eosse. & 6.453t+ \\
\hline FMEA & $70 \mathrm{E}$ & azt & $\pi 01$ & 120. & 24.4. & 801 \\
\hline $\operatorname{spN}$ & 06463 & 08192 & $0,6437$. & 0.000 & 0,036 & bank \\
\hline
\end{tabular}

There are 6 water resources allocation plans in table 1 . Plan 1 focuses on water-saving which is based on the present water supply condition and only concerns how much water can be saved. Municipal sewage is processed under the lowest standard of the environment and the processed water cannot be reused. The qualitative analysis shows that this plan is not able to meet the requirements of the 2010 economic plans for northern areas and improve people's living standard there. So it is hard to increase the supporting capacity of regional water resources for economic development only by saving water.

Plan 2 not only saves water but also recycles wastewater. The plan aims to improve the water-saving level and reuse rate of wastewater in the current situation without adding extra investment. Though water-saving and wastewater recycling are priorities to solve water shortage problem, it cannot be the best plan because the total water resources of northern China is limited.

Besides water saving and wastewater recycling, Plan 3 proposes a local water project and plans to divert water from Yellow River. The plan does alleviate water shortage problem to some extent in a certain period of time, but the cost is that much more investment is needed. What's more, a simulated result of water supply and demand balance shows that the groundwater would be seriously over exploited.
What plan 4 differs from plan 3 is a project to divert 7.5 billion $\mathrm{m} 3$ of water from Yangtze River. The quantity of water diversion in the project is relatively small which can only alleviate the water shortage problem of cities benefited from the South-North Water Diversion Project. And compared with the first 3 plans, plan 4 requires large investment. So it is not an ideal one from the investment and anticipated benefits aspects.

Plan 5 is similar to plan 4 , but plan 5 increases investment, but it can slove the water shortages problem of northern China fundamentally. So plan 5 is preferred.

As for plan 6, water-saving, wastewater recycling, water diversion from Yellow River and are included. Though under such circumstances the long-term water shortage problem of northern China can be solved basically, other problems like big investment and the water environmental problems of the east line still exit. Moreover, the first phase project of the east line cannot provide water supply until 2015, and before 2010, water shortages in the north areas of Shandong was already severe. So compared with plan 4 and plan 5, the advantages and disadvantages of plan 6 is in-between.

\section{CONCLUSION}

Multi-attributes decision-making method based on fuzzy set pair analysis can effectively describe and process uncertain information of decisions in water resources management. The target of the research mainly focuses on water resources allocation plans of northern China and study theories and methods of the comprehensive evaluations of these plans by applying the multi-attributes decision-making method, so as to provide a new way to solve uncertain decision-making problems of regional water resources, develop and culminate the research for uncertain theoretical methods of soft multi-attributes decision-making methods.

\section{REFERENCES}

[1] Xu Xinyi,Wang Hao, "Macro-economy water resources planning theory and method in north China". The Yellow River water conservancy press, 1997

[2] Y.L. Jiang, C.F. Xu, Y.Yao, K.Q. Zhao, "Systems information in set pair analysis and its applications', Proceedings of International Conference on Machine Learning and Cybernetics, vol. 3, pp. 1717-1722, 2004

[3] K.Q. Zhao. "Description and processing of uncertain information using set pair analysis", Information and control, vol.24, pp. 162166,1995

[4] Huang Guozhong,Wu Zhongguang, Yang Cansheng, "Research on construction safety evaluation based on Fuzzy-Set Pair Analysis model",International Conference on Manufacturing Science and Technology (ICMST 2011),vol.383-390,pp.6587-6593,2012.

[5] Yang Junjie, Xue Liqin, "The new connection numbers ranking methods on set pair", Proc. of SPIE, pp. 7498:74984M1-6, 2009

[6] Qing-kui Cao, Li-jie Li, Bing Yu, "Application of dynamic set-pair analysis in coal and gas outburst prediction",Journal of Coal Science and Engineering (China), Vol.14, pp. 77-80,2008

[7] Xia Ji, Longshu Li, Shengbing Chen, Yi Xu, "An United Extended Rough Set Model Based on Developed Set Pair Analysis Method", Artificial Intelligence and Computational Intelligence Lecture Notes in Computer Science, Vol.5855, pp. 9-17, 2009

[8] J. J. Yang, "Multi-objective Decision-making Methods for Reservoir Flood Operation Based on Fuzzy Connection Number', Journal of Information and Decision Science, vol.3,pp. 217-225, 2008 
[9] Yang Junjie, Zhou Jianzhong, Li Ying hai, "Multi-objective decision making on reservoir flood operation by using fuzzy connection numbers", J . Huazhong Univ. of Sci. \& Tech. (Natural Science Edition), vol.37,pp.101-104, 2009.

[10] Ruan Benqing, "Basin water resource management", Beijing:Science Press, 2001.
[11] YANG Guo-hua,CUI Bin, "The Application of Entropy Weight Method to Evaluation of the Sustainable Utilization of Water Resources", Mathematics in Practice and Theory,vol. 41,pp. 8-12, 2011. 